\title{
Insights into factors sustaining persistence of high malaria transmission in forested areas of sub-Saharan Africa: the case of Mvoua, South Cameroon
}

\author{
Dominique Mieguim Ngninpogni ${ }^{1,2}$, Cyrille $\mathrm{Ndo}^{2,3,4^{*}}$, Patrick Ntonga Akono ${ }^{5}$, Anicet Nguemo ${ }^{2,5}$, \\ Amine Nguepi ${ }^{2,5}$, Danale Rosine Metitsi ${ }^{1,2}$, Jeannette Tombi ${ }^{1}$, Parfait Awono-Ambene ${ }^{2}$ \\ and Charles Félix Bilong Bilong ${ }^{1}$
}

\begin{abstract}
Background: In Mvoua, a village situated in a forested area of Cameroon, recent studies have reported high prevalence of Plasmodium falciparum infection among the population. In order to understand factors that can sustain such a high malaria transmission, we investigated the biology of Anopheles vectors and its susceptibility to insecticides, as well as long-lasting insecticidal net (LLIN) coverage, use and bio-efficacy.

Methods: A longitudinal entomological survey was conducted from July 2018 to April 2019. Adult mosquitoes were collected using the human landing catch (HLC) method and identified using morphological and molecular techniques. Anopheles gambiae (s.l.) larvae were sampled from several stagnant water pools throughout the village and reared to generate $\mathrm{F} 1$ adults. The presence of $P$. falciparum circumsporozoite antigen was detected in the heads and thoraces of mosquitoes collected as adults using an enzyme-linked immunosorbent assay. The insecticide susceptibility status of the local An. gambiae (s.l.) F1 population to the pyrethroid insecticides deltamethrin $0.5 \%$ and permethrin $0.75 \%$ was determined using World Health Organization-tube bioassays, while the frequency of the knockdown resistance $(k d r)$ mutation was determined by PCR. Coverage, use and physical integrity of LLINs were assessed in households, then cone assays were used to test for their bio-efficacy on both the reference insecticide-susceptible Kisumu strain and on field F1 An. gambiae (s.l.)
\end{abstract}

Results: In total, 110 Anopheles mosquitoes were collected, of which 59.1\% were identified as Anopheles funestus (s.l.), $38.18 \%$ as An. gambiae (s.l.) and $2.72 \%$ as An. ziemanii. Anopheles funestus was the most abundant species except in the long rainy season, when An. gambiae (s.l.) predominated (65.8\%). In the dry seasons, vectors were principally endophagous (76\% of those collected indoors) while they tended to be exophagous (66\% of those collected outdoors) in rainy seasons. High Plasmodium infection was observed in An. gambiae (s.l.) and An. funestus, with a circumsporozoitic rate of 14.29 and $10.77 \%$, respectively. Anopheles gambiae (s.l.) was highly resistant to pyrethroid insecticides (mortality rates: $32 \%$ for permethrin and 5\% for deltamethrin) and harbored the kdr-L1014F mutation at a high frequency (89.74\%). Of the 80 households surveyed, only $47.69 \%$ had achieved universal coverage with LLNs. Around $70 \%$ of the LLINs

\footnotetext{
*Correspondence: cyrndo@yahoo.fr

${ }^{2}$ Institut de Recherche de Yaoundé (IRY), Organisation de Coordination

pour la lutte Contre les Endémies en Afrique Centrale (OCEAC), P.O.

Box 288, Yaoundé, Cameroon

Full list of author information is available at the end of the article
}

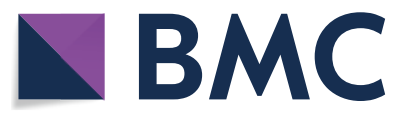

(c) The Author(s) 2021. This article is licensed under a Creative Commons Attribution 4.0 International License, which permits use, sharing, adaptation, distribution and reproduction in any medium or format, as long as you give appropriate credit to the original author(s) and the source, provide a link to the Creative Commons licence, and indicate if changes were made. The images or other third party material in this article are included in the article's Creative Commons licence, unless indicated otherwise in a credit line to the material. If material is not included in the article's Creative Commons licence and your intended use is not permitted by statutory regulation or exceeds the permitted use, you will need to obtain permission directly from the copyright holder. To view a copy of this licence, visit http://creativeco mmons.org/licenses/by/4.0/. The Creative Commons Public Domain Dedication waiver (http://creativecommons.org/publicdomain/ zero/1.0/) applies to the data made available in this article, unless otherwise stated in a credit line to the data. 
sampled were in poor physical condition, with a proportionate hole index $>300$. Of the ten LLNs tested, eight were effective against the An. gambiae reference insecticide-susceptible Kisumu strain, showing mortality rate of $>80 \%$, while none of these LLINs were efficient against local An. gamabie (s.l.) populations (mortality rates $<11.5 \%$ ).

Conclusion: A combination of elevated P. falciparum infection in Anopheles vector populations, insufficient coverage and loss of effectiveness of LLINs due to physical degradation, as well as high resistance to pyrethroid insecticides is responsible for the persistence of high malaria transmission in forested rural area of Mvoua, Cameroon.

Keywords: Malaria prevalence, Insecticide resistance, Anopheles, Long lasting insecticide treated net, Mvoua

\section{Background}

Malaria remains the most endemic parasitic disease worldwide. The African continent is by far the most malaria-affected region, with approximately $93 \%$ of all cases (213 million) and 94\% of deaths worldwide [1]. In Cameroon, malaria is highly endemic and represents an important health threat, particularly for the most vulnerable groups, including children aged $<5$ years, pregnant women and people living with human immunodeficiency virus/acquired immunodeficiency syndrome [2]. The epidemiology of malaria is heterogeneous throughout the country, with high and perennial transmission occurring in the forest, coastal and humid savanna areas and low transmission in the highlands, while the Sahel and dry savanna regions are areas of seasonal transmission. Whatever the area, the disease is mainly caused by the Plasmodium falciparum parasite, with mosquitoes from the Anopheles gambiae complex and An. funestus group being its major vectors [3]. Both species have wide geographic distributions and co-exist over much of their range. Their efficiency as malaria vectors is due to their high dependence on humans for their feeding, resting, and to a certain extent, breeding habitats [4].

The fight against malaria relies mainly on vector control through the use of long-lasting insecticidal nets (LLINs) and indoor residual spraying of insecticides. To this end, more than 20 million of LLINs have been distributed to the Cameroonian population since 2011. This scale-up of LLINs across the country resulted in a significant decrease in reported malaria cases, from 41 to $24.3 \%$, between 2000 and 2015. During this same time span, it was estimated that there was a $54 \%$ decrease in malaria-related mortality, from about 13,000 to 6000 deaths per year. However, despite these gains, parasitological and entomological studies conducted in the rural settings of Cameroon still reveal high prevalences of Plasmodium infection in both the human and mosquito hosts. This is especially the case in the forested areas found in the southern part of the country. Such high prevalences bring into question the effectiveness of the LLINs distributed as well as possible changes in vector biology [5-7].
Effective malaria vector control is reliant on knowledge of the local vector species and their susceptibility to insecticides. Generally, within a given area, the biology of each species is unique in many respects, including the sites where larvae develop, adult mosquito behavior (especially human-biting behavior), susceptibility to Plasmodium parasites, the ability to transmit these parasites and their resistance profile to insecticides [8]. Therefore, a failure to appreciate the biological complexities that allow vector populations to sustain malaria transmission and to resist or evade interventions could substantially impede control efforts [9]. Moreover, there is also a critical need for ongoing monitoring of the coverage, usage, quality and durability of vector-control interventions following their deployment. Periodic collection of such data is essential to inform vector control strategies and track their impact on malaria transmission $[9,10]$.

The present study was conducted in Mvoua, a village situated in the forested region of Cameroon where high malaria prevalence has been reported [7]. Preliminary investigations have been carried out at this site previously, with the aim to understand factors contributing to such a high prevalence by assessing population knowledge, attitudes and practices related to malaria transmission and disease case management. In the study reported here, we investigated other key factors which could influence malaria epidemiology, such as Anopheles biology and susceptibility to insecticides, and LLIN coverage, use and effectiveness, with the aim to contribute to malaria surveillance in Cameroon [11, 12].

\section{Methods}

\section{Study area}

The study was conducted in Mvoua $\left(4^{\circ} 4^{\prime} \mathrm{N} ; 11^{\circ} 25^{\prime} \mathrm{E}\right)$, a village situated in Okola district in the Central region of Cameroon. This village of about 300 inhabitants is located approximately $35 \mathrm{~km}$ from Yaoundé, the political capital of the Republic of Cameroon. The vegetation cover is made up of a semi-deciduous forest subjected to a Guinean-equatorial climate type, with mean annual rainfalls ranging from 1600 to $1800 \mathrm{~mm}$. This climate is characterized by two distinct rainy seasons extending from March to May (short rainy season) and from August 
to November (long rainy season), and by two dry seasons extending from June to July (short dry season) and from December to February (long dry season) [13]. A previous malaria diagnosis survey conducted in Mvoua reported that malaria remains highly endemic in this locality, with infection prevalence of $60 \%$ in children aged between 4 and 10 years [7].

\section{Adult mosquito collection}

Collections of adult host-seeking mosquitoes were undertaken employing both the CDC light trap (CDCLT) and human landing catch (HLC) methods. Because no mosquito was collected using the CDC-LTs after two consecutive nights of sampling, this method was discarded.

Sampling using the HLC method was performed in ten randomly selected houses situated at least $100 \mathrm{~m}$ apart. The method involved persons sitting with their lower legs exposed and then collecting mosquitoes that just landed on them [14]. Adult mosquitoes were sampled both indoors and outdoors during two consecutive nights, once per each of the four seasons. Mosquitoes collected each hour were placed into separate bags, labeled accordingly and brought back to the laboratory for further analysis. To avoid bias due to sleep and tiredness, one team of collectors worked from 18:00 h to midnight, and was replaced by another team which worked from midnight to $6: 00 \mathrm{~h}$.

\section{Mosquito identification and detection of Plasmodium infection}

Adult mosquitoes collected using the HLC method were identified based on morphological criteria following the identification keys of Gillies and De Meillon [15] and Gillies and Coetzee [16]. Female Anopheles mosquitoes were sorted from other Culicinae, stored in Eppendorf tubes with silica gel (desiccant) and taken to the medical entomology laboratory of OCEAC (Organisation de Coordination pour la lutte Contre les Endémies en Afrique Centrale) for subsequent analyses. Heads and thoraces were processed for detection of $P$. falciparum circumsporozoite protein (CSP) using an enzyme-linked immunosorbent assay (ELISA) method as previously described $[17,18]$. DNA extracted from the abdomen and legs [19] was used for the molecular identification of sibling species by PCR, as described previously [20, 21].

\section{Insecticide bioassays and knockdown resistance detection} Larvae of An. gambiae (s.l.) were collected in stagnant pools of water and reared in the insectary of the medical entomology laboratory of OCEAC. F1 adults that emerged from those larvae were fed with $10 \%$ sucrose solution made by dissolving $100 \mathrm{~g}$ of ordinary white sugar in $1 \mathrm{~L}$ of water [22]. Anopheles funestus was not tested due to the low number of adults obtained following larval collections and rearing. The susceptibility of the $\mathrm{F} 1$ adults to $0.75 \%$ permethrin and $0.05 \%$ deltamethrin, both pyrethroid pesticides, was assessed using a World Health Organization (WHO) standard test procedure [23]. Tests were performed at $25 \pm 2{ }^{\circ} \mathrm{C}, 80 \% \pm 10 \%$ relative humidity $(\mathrm{RH})$. For each insecticide, four batches of 20-25 field F1 females, aged between 2 and 5 days, were exposed to insecticide-impregnated papers in WHO testtube for $1 \mathrm{~h}$. At the same time, two batches of the same number of mosquitoes were exposed to untreated papers as control. At the end of the insecticide exposure period, the number of knocked-down mosquitoes was recorded, following which the mosquitoes were transferred into holding tubes. Cotton balls that had first been soaked in a $10 \%$ sugar solution and then the moisture squeezed out were placed at the mouth of the tubes. The mortality was recorded $24 \mathrm{~h}$ later. Mortality rate in the tested samples was corrected using Abbott's formula [24], when the mortality in the control tubes varied between 5 to $20 \%$. The knockdown resistance $(k d r)$ mutation L1014F, which is responsible of cross resistance to DDT (dichlorodiphenyltrichloroethane) and pyrethroids was genotyped using the protocol described by Martinez-Tores et al. [25].

\section{Bed net coverage, use and maintenance}

Bed net ownership was investigated in 80 of 97 the households that currently make up the village through visual inspection. The heads of these households or their representatives were questioned on their use of nets and their maintenance. The number of people living in each house was recorded to estimate net coverage. Household net ownership was defined as the percentage of households owning at least one LLIN. Net coverage defined as the percentage of households with at least one LLIN for every two people was also determined.

\section{Bed net integrity and bio-efficacy}

Ten bed nets were randomly collected from ten selected houses and immediately replaced by new ones. The physical integrity of the nets collected was determined by counting, per category, the number of holes that were approximately the size of a person's thumb, fist or head, or larger than a head, on any of the four faces and the top of the bed net $[26,27]$. The proportionate hole index (pHI) was calculated using the WHO Pesticide Evaluation Scheme (WHOPES ) guidelines [11] and nets were classified into four classes accordingly [28, 29]. Nets with a pHI < 25 were classified as "good"; those with a pHI ranging between 25 and 174, as "fair"; those nets with a pHI ranging from 175 to 299, as "mediocre"; and those with a $\mathrm{pHI}>300$, as "poor". 
Cone assays were performed on each net to test for its bio-efficacy as described in WHO guidelines [30]. Four cones were fixed by their widest opening onto four different parts of each face (4 sides and 1 roof) of each net. Ten unfed An. gambiae (s.l.) female mosquitoes aged 2-5 days were introduced into each cone using a mouth aspirator, for a total of 200 specimens per net. After $3 \mathrm{~min}$ of exposure, the mosquitoes were removed from the cones, then transferred into paper cups and fed with a $10 \%$ sugar solution. The assay was conducted at $25 \pm 1{ }^{\circ} \mathrm{C}, 80 \% \pm 5 \%$ $\mathrm{RH}$, and the number of mosquitoes knocked-down and dead were recorded after $60 \mathrm{~min}$ and $24 \mathrm{~h}$, respectively. An untreated net was used as the negative control.

\section{Data analysis}

Data were analyzed using SPSS software version 25 (IBM Corp., Armonk, NY, USA). The entomological parameters that were considered were: (i) human-biting rate (HBR), i.e. the average number of bites received per person per night; (ii) infection rate, i.e. the proportion of mosquitoes found with Plasmodium circumsporozoite antigen in the heads and thoraces; (iii) entomological inoculation rate (EIR), i.e. the product of the HBR and circumsporozoite rate. Chi-square statistics was used to compare mosquito densities between seasons while mosquitoes' seasonal aggressiveness (HBR) were compared by the Kruskal-Wallis test. Differences were considered statistically significant at $P<0.05$.

\section{Results}

\section{Composition and abundance of Anopheles mosquitoes}

In total, 129 adult mosquitoes were collected during eight nights. These belonged to four genera, of which Anopheles $(N=110 ; 85.27 \%)$ was the most prevalent, followed in decreasing order of prevalence by Mansonia $(N=11 ; 8.53 \%)$, Aedes $(N=6 ; 4.65 \%)$ and Culex $(N=$ 2; 1.55\%). Three Anopheles species were collected namely An. funestus (s.l.) (59.1\%), An. gambiae (s.l.) (38.18\%) and An. ziemanii (2.72\%). Anopheles. sp were most abundant in the short dry season followed by the long rainy season (49.09\% of the total Anopheles collected) and the long rainy season $(34.54 \%)$.

In terms of seasonal species abundance, An. funestus was the most abundant species collected (59.1\%) over the period of study, with the exception of the long rainy season when An. gambiae (s.l.) predominated (Fig. 1).

\section{Entomological parameters}

The HBR was low during the entire study period, with the number of bites per person per night being less than one bite (0.93) (Table 1). The HBR of An. funestus (s.l.) was higher (0.55) than that of An. gambiae (s.l.) (0.35) $\left(x^{2}=7.520, d f=1, P<0.05\right)$. In terms of season and irrespective of the species, the difference in HBR was statistically significant $\left(x^{2}=2.58, d f=3, P<0.05\right)$, with the highest HBR value (1.92) observed during the short dry season and the lowest HBR value (0.17) observed during the short rainy season. Anopheles funestus (s.l.) was recorded as being the most aggressive (HBR 1.5) mosquito species during the short dry season, whereas $A n$. gambiae (s.l.) had the higher HBR during the long rainy season (HBR: 0.83). During the two dry seasons, these two vectors were principally caught indoors $(76 \%)$, while in rainy seasons, they were mostly found biting outdoors (66\%) (Fig. 2).

During the study period, most Anopheles bites from An. funestus (s.l.) and An. gambiae (s.l.) occurred between 21:00 $\mathrm{h}$ and 3:00 $\mathrm{h}$, with the major peak being observed between 23:00 $\mathrm{h}$ and 00:00 $\mathrm{h}$ and the minor peak observed between 2:00 $\mathrm{h}$ and 3:00 $\mathrm{h}$ (Fig. 3).

\section{Mosquito infection and malaria transmission}

Of the 110 samples tested, 13 (11.81\%) were infected by $P$ falciparum (Table 1 ). The circumsporozoite index (ICSP) was $10.77 \%$ for An. funestus (s.l.) and $14.29 \%$ for An. gambiae (s.l.), and both ICSP were not statistically different $(\chi 2=0.296, d f=1, P>0.05)$. The short dry season appeared to be the period of the year when the infection rate was the highest (ICSP 18.51\%; $\chi^{2}=3.86, d f=3$, $P<0.05)$.

The overall EIR during the study was 2.7 infective bites/human/month, and there was no significant difference between the monthly EIRs of An. funestus (s.l.) (1.5 infective bites/human/month) and An. gambiae (s.l.) (1.2 infective bites/human/month) $(\mathrm{x} 2=8.54 ; d f=11$, $P>0.05$ ) (Table 1).

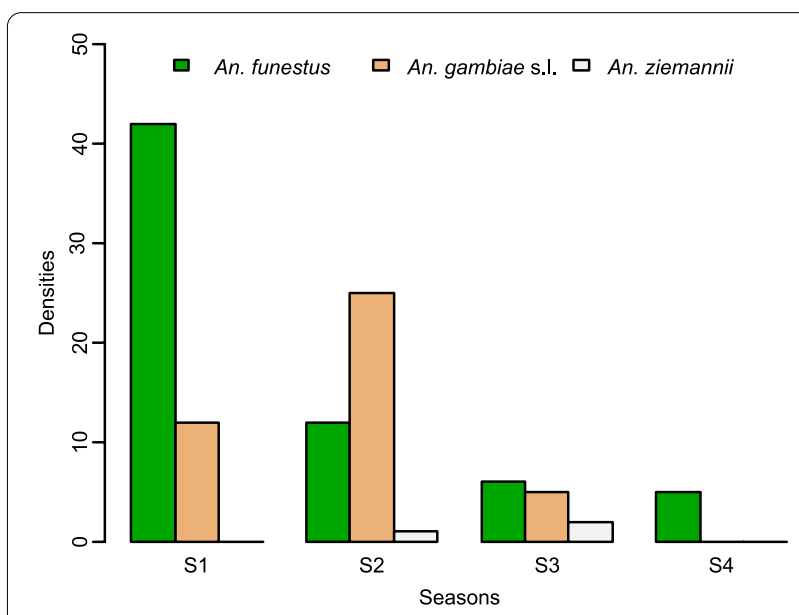

Fig. 1. Seasonal relative abundance of Anopheles mosquito species in Mvoua. S1 short dry season, S2 long rainy season, S3 long dry season, $\$ 4$ short rainy season 
Table 1 Plasmodium circumsporozoite index, human biting rate and monthly entomological inoculation rate of Anopheles species in Mvoua between August 2018 and April 2019

\begin{tabular}{|c|c|c|c|c|c|}
\hline \multirow[t]{2}{*}{ Anopheles species } & \multirow[t]{2}{*}{ Tested $(N)$} & \multirow[t]{2}{*}{ Positive $(N)$} & \multicolumn{3}{|l|}{ Entomological parameters } \\
\hline & & & $\begin{array}{l}\text { Plasmodium circumsporozoite } \\
\text { index (\%) }\end{array}$ & Human biting rate & $\begin{array}{l}\text { Entomological } \\
\text { inoculation rate/ } \\
\text { month }\end{array}$ \\
\hline An. funestus (s.l.) & 65 & 7 & 10.77 & 0.55 & 1.5 \\
\hline An.gambiae (s.l.) & 42 & 6 & 14.29 & 0.35 & 1.2 \\
\hline An. ziemanii & 3 & 0 & 0 & 0.02 & NC \\
\hline Total & 110 & 13 & $11.81 \%$ & 0.93 & 2.7 \\
\hline
\end{tabular}

Human-biting rate (HBR) is the average number of bites received per person per night; (ii) Plasmodium circumsporozoite index (infection rate) is the proportion of mosquitoes found with Plasmodium circumsporozoite antigen in the heads and thoraces; entomological inoculation rate is the product of the HBR and circumsporozoite rate

NC not calculated

\section{Mosquito susceptibility to permethrin and deltamethrin}

A total of 100 An. gambiae (s.l.) mosquitoes were exposed to each of the insecticides namely permethrin and deltamethrin. At the end of the exposure period $(1 \mathrm{~h}), 32$ and $5 \%$ mosquitoes were knocked-down for deltamethrin and permethrin, respectively. Low mortality, indicating a high level of resistance, was recorded for both insecticides, with a mortality rate of $33 \%$ for permethrin and $5 \%$ for deltamethrin. By contrast and as expected, the reference insecticide susceptible Kisumu strain used as control was fully susceptible to both insecticides (100\% mortality).

The molecular studies performed on adult mosquitoes collected using the HLC method showed An. funestus (s.s) is the only member of the An. funestus group present

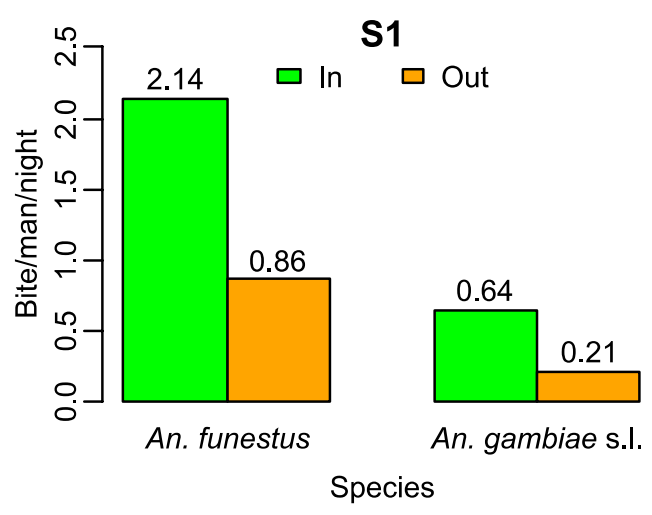

\section{S2}

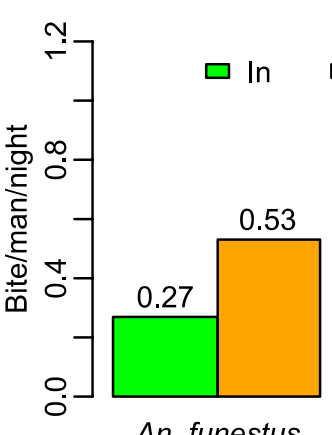

$\square$ Out

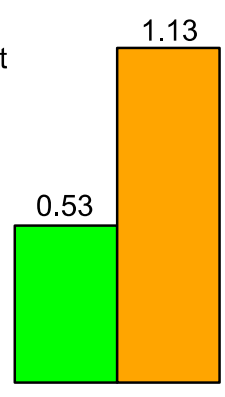

An. gambiae s.I.

Species

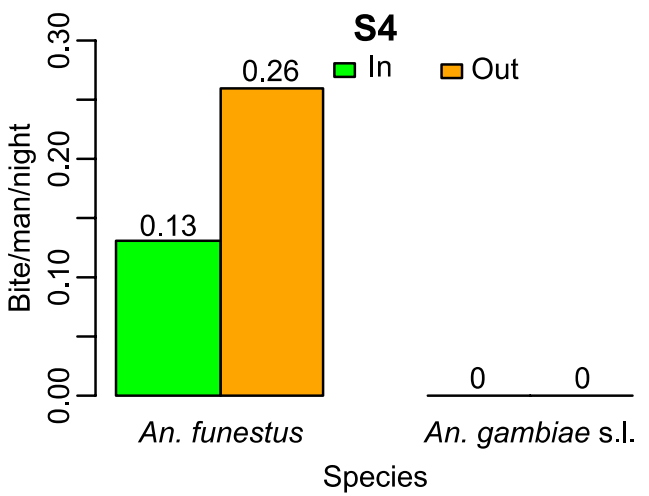

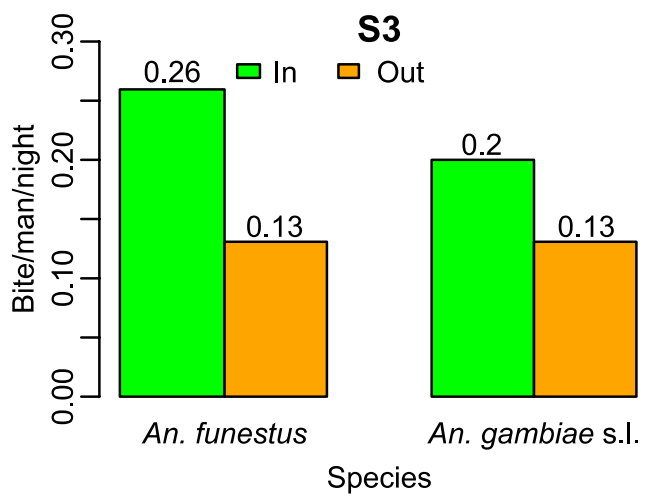

Fig. 2 Seasonal variation in human biting behavior of malaria vectors in Mvoua from August 2018 to April 2019. In Inside (homes), Out outside, S1-S4 as defined in Fig. 1 


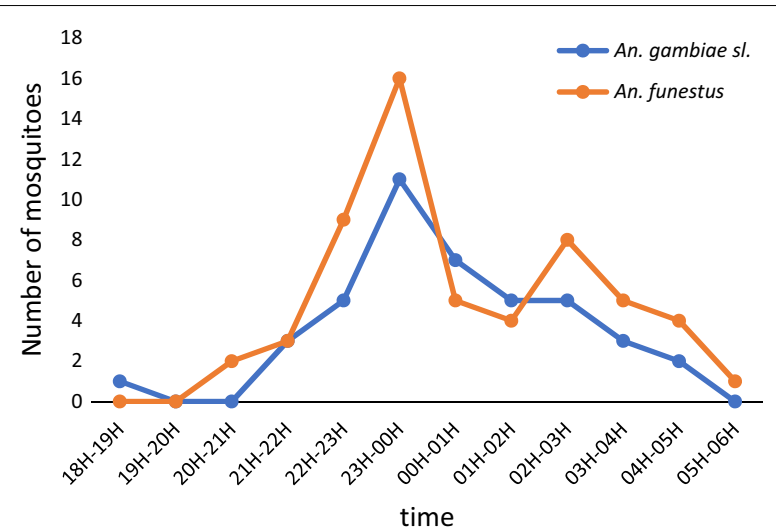

Fig. 3 Anopheles funestus and An. gambiae (s.l.) night-biting cycle in Mvoua from August 2018 to April 2019

in Mvoua. For the An. gambiae complex, An. gambiae was the most abundant species (71.8\%) compared to $A n$. coluzzii (28.2\%). The $k d r$ L1014F mutation was found to be present at high frequencies in both An. gambiae (98.21\%) and An. coluzzii (77.27\%) (Table 2).

\section{Possession, coverage and use of LLINs}

In general, $81.25 \%$ of the households inspected possessed at least one LLIN. Despite this high level of ownership, the proportion of households that met the ratio of one net for two persons was only $47.69 \%$. Fortunately, $81.54 \%$ of the people interviewed affirmed they used their bed nets every night (Table 3). Of the LLINs available, 92.3\% were acquired during the government free mass distribution campaigns of 2011-2012 and 2015-2016. Although almost $70 \%$ of the study population affirmed that they have been educated by the public health community agents during the distribution campaigns, only $10.52 \%$ knew bed nets should be dried in the shade before usage or after washing. Moreover, $56.46 \%$ of respondents had washed their bet nets at least once; $63.15 \%$ used water and ordinary soap while $36.85 \%$ used detergents soap and bleach (Table 3).

\section{Physical integrity and effectiveness of LLINs}

Ten LLINs aged 3-7 years old were sampled to assess their physical integrity and bio-efficacy. A total of 161 holes belonging to all the four different types described by WHOPES (the size of a person's thumb, fist or head, or larger than a head) were counted, with a mean of 17 holes per bed net. The proportion of these holes per type was $52.79 \%$ (thumb size), 32.29\% (fist size), 9.93\% (head size) and $4.96 \%$ (large than head size). Of the ten LLINs examined, seven $(70 \%)$ were damaged and were found to be in poor condition ( $\mathrm{pHI}>300)$ (Table 4).

A total of 2000 specimens of the An. gambiae (s.l.) susceptible Kisumu strain were exposed to the ten bed nets. Eight of these nets were effective against this strain, with mortality rates $>80 \%$. Exposure of the same number of An. gambiae (s.l.) field F1 mosquitoes to these LLINs revealed that they were all ineffective, with mortalities ranging from 0 to $11.5 \%$ (Table 4 ).

\section{Discussion}

The results of this study show that the Culicidaeaggressive fauna in our study site consists of four genera, namely Anopheles, Mansonia, Aedes and Culex. The predominance of the Anopheles genus was likely due to our study locality being situated in a rural area. Indeed, several previous studies conducted in forested localities in Cameroon have reported the proliferation of mosquitoes of Anopheles genus in rural settings [31], while those of Culex and Aedes genera are predominant in highly anthropized and polluted urban areas [32]. Moreover, the use of the HLC method, which is a method for sampling anthropophilic mosquitoes, could have also favored the collection of athrophophilic Anopheles over other mosquito species [33-35]. However, while HLC remains the gold standard method for measuring human exposure to mosquito bites and, consequently, malaria transmission, it should be noted that results based on sampling using this method can be biased due to natural human variations in attractiveness to mosquitoes [36, 37].

Three main vector species belonging to the An. funestus group and An. gambiae complex were collected in this study. Anopheles funestus was more abundant throughout the study period, while two sibling species of the An. gambiae complex (An. coluzzii and An. gambiae) were mostly collected during the long rainy season. The pullulating period of An. funestus is usually observed at

Table 2 Anopheles gambiae complex species composition and the frequency of the knockdown resistance L1014F mutation

\begin{tabular}{|c|c|c|c|c|c|c|c|}
\hline \multirow[t]{2}{*}{ Anopheles species } & \multicolumn{2}{|c|}{ Composition } & \multicolumn{3}{|c|}{ kdr-L1014 F genotypes } & \multicolumn{2}{|c|}{ kdr-L1014 F alleles (\%) } \\
\hline & $N$ & $\%$ & $\mathrm{RR}$ & RS & SS & $\mathrm{R}$ & $\mathrm{S}$ \\
\hline An.gambiae & 28 & 71.8 & 27 & 1 & 0 & 98.21 & 1.79 \\
\hline An. coluzzii & 11 & 28.2 & 8 & 1 & 2 & 77.27 & 22.73 \\
\hline Total & 39 & 100 & 35 & 2 & 2 & 92.31 & 7.69 \\
\hline
\end{tabular}

kdr-L1014F, Knockdown resistance L1014F mutation; R resistance; S, susceptible 
Table 3 Origin, use and maintenance of long-lasting insecticidal nets

\begin{tabular}{|c|c|c|}
\hline Variables related to LLIN & N & Frequency (\%) \\
\hline \multicolumn{3}{|l|}{ Possession } \\
\hline Yes & 65 & 81.25 \\
\hline No & 15 & 18.75 \\
\hline \multicolumn{3}{|l|}{ Origin } \\
\hline Government & 60 & 92.3 \\
\hline Market & 5 & 7.7 \\
\hline \multicolumn{3}{|l|}{ Installed } \\
\hline Yes & 59 & 90.76 \\
\hline No & 6 & 9.24 \\
\hline \multicolumn{3}{|l|}{ Presence per 2 persons } \\
\hline Yes & 31 & 47.7 \\
\hline No & 34 & 52.3 \\
\hline \multicolumn{3}{|l|}{ Usage } \\
\hline Every night & 53 & 81.54 \\
\hline Not every night & 12 & 18.46 \\
\hline \multicolumn{3}{|c|}{ Education received on LLINs during distribution } \\
\hline Yes & 45 & 69.92 \\
\hline No & 20 & 30.78 \\
\hline \multicolumn{3}{|l|}{ Had LLIN been washed } \\
\hline Yes & 38 & 58.46 \\
\hline No & 27 & 41.54 \\
\hline \multicolumn{3}{|l|}{ Substance used for washing } \\
\hline Ordinary soap & 24 & 63.15 \\
\hline Detergent and bleach & 14 & 36.85 \\
\hline \multicolumn{3}{|l|}{ Drying place } \\
\hline In sun & 34 & 89.48 \\
\hline In shade & 4 & 10.52 \\
\hline
\end{tabular}

LLIN, Long-lasting insecticidal net the end of the rainy season and up to the middle of the dry season $[38,39]$ while, in contrast, An. gambiae (s.l.) takes over as predominant species during the rainy seasons. It is well known that the intensity and frequency of rainfall during rainy seasons contribute greatly to the formation of temporary water pools, which represent typical breeding sites for An. gambiae (s.l.) [40, 41].

The values of the entomological parameters determined in our study further support findings from a previous parasitological survey conducted in Mvoua, also indicating the occurrence of high malaria transmission in this locality. The Plasmodium circumsporozoite rate determined by the ELISA was high in both vector species, confirming that mosquitoes from both the $A n$. funestus group and An. gambiae complex are major vectors of malaria in the forested regions of Cameroon [42, 43]. Similar levels of Plasmodium infection have been recently reported by Ndo et al. [7] in Obout, another locality situated within the forested regions of central Cameroon, highlighting the persistence of high levels of malaria transmission in this environment, despite the intensive control efforts that have been deployed over the years. The forest environment actually offers suitable conditions for the proliferation of mosquito vectors throughout the year due to its climate, which is rainy, thereby conducive to the formation of temporary Anopheles breeding sites [44].

The high levels of infection in malaria vectors observed in this study are in striking contrast to the high possession rate of LLINs, which should have reduced malaria transmission by protecting individuals from infectious bites and by minimizing the probability that a mosquito survives throughout the entire extrinsic

Table 4 Hole index and mortality of An. gambiae (s.l.) after being exposed to the long-lasting insecticidal nets

\begin{tabular}{|c|c|c|c|c|c|c|c|}
\hline \multirow[t]{2}{*}{ Nets } & \multirow[t]{2}{*}{ Date of impregnation } & \multirow[t]{2}{*}{ Brand } & \multicolumn{2}{|c|}{ Physical integrity of LLIN } & \multicolumn{2}{|c|}{ Bio-efficacy of LLIN (\%) } & \multirow[t]{2}{*}{ Decision } \\
\hline & & & $\mathrm{pHI}$ & Status & $\begin{array}{l}\text { Kisumu control } \\
\text { strain }\end{array}$ & Field strain & \\
\hline Net 1 & October 2015 & Olyset & 0 & Good & 83.50 & 3.50 & Not efficient \\
\hline Net 2 & October 2015 & Olyset & 916 & Poor & 80.50 & 00.50 & Not efficient \\
\hline Net 3 & February 2011 & Permanet & 1939 & Poor & 69.50 & 2.50 & Not efficient \\
\hline Net 4 & February 2011 & Permanet & 581 & Poor & 88.00 & 11.00 & Not efficient \\
\hline Net 5 & February 2011 & Permanet & 13 & Good & 99.00 & 8.00 & Not efficient \\
\hline Net 6 & October 2015 & Olyset & 651 & Poor & 85.00 & 2.50 & Not efficient \\
\hline Net 7 & October 2011 & Permanet & 2225 & Poor & 72.40 & 3.50 & Not efficient \\
\hline Net 8 & October 2011 & Permanet & 1 & Good & 98.00 & 9.50 & Not efficient \\
\hline Net 9 & May 2014 & Royal sentry & 1180 & Poor & 95.00 & 11.50 & Not efficient \\
\hline Net 10 & October 2015 & Olyset & 1395 & Poor & 87.50 & 2.00 & Not efficient \\
\hline
\end{tabular}


incubation period of the Plasmodium parasite. Our findings indicate rather that (i) Anopheles mosquitoes still have access to human hosts to ingest or transmit Plasmodium parasites during blood intake, and (ii) vectors still live long enough to enable the parasite to develop from the gametocyte to the infectious sporozoite stages. These findings therefore bring the efficiency of LLNs in the surveyed locality into question, and several observations from this study could help to elucidate this situation. Firstly, we observed an insufficient coverage in LLINs. Among the households inspected, although a high level of possession of LLINs was observed, the proportion of households that met the universal coverage as defined by WHO (one net for two persons) was still below $50 \%$, and far from the targeted rate of $80 \%$ set by the Cameroonian government [45].

Secondly, LLINs were not optimally used. Although $81.54 \%$ of the respondents affirmed that they used their bed nets every night, it was noted that the use of LLINs varied depending of the season. A reduction in LLINs use is often observed during the dry season due to heat, and mosquitoes are more likely to migrate inside at this time, therefore increasing the probability of receiving infective bites [46]. In contrast, when the weather cools down, the proportion of people sleeping under bet nets scales up. The repellent effect of the nets could then drive mosquitoes outside, decreasing the probability of receiving an infective bite. Such behavior at the population level might have lead to a trend towards endophagy for An. gambiae (s.l.) and An. funestus (s.s.) during the two dry seasons, whereas they were more exophagous during the two rainy seasons. In addition, in our study, the short dry season appeared to be the period of the year when malaria transmission was higher.

Thirdly, LLINs could have lost their effectiveness due to physical degradation and decreased susceptibility of local vector populations to insecticides impregnated into the nets. The sampled LLINs were 3 to 7 years old, and $70 \%$ were found to be in poor condition, with large holes, which may have impeded them providing physical protection from mosquitoes [47]. We also noted that most respondents mentioned having washed their nets using detergent and then drying them directly in the sun. According to Morris et al. [48], direct sunlight is harmful to pyrethroid-based insecticides because ultraviolet rays break down pyrethrin molecules, thereby rendering the insecticide ineffective. However, the role played by sunlight in enhancing or rendering pyrethrin ineffective is still controversial. Nevertheless, bio-efficacy tests showed that eight of the ten bed nets tested were still optimally effective ( $\geq 80 \%$ mortality) against the susceptible laboratory strain of An. gambiae (reference susceptible Kisumu strain). Therefore, in addition to their physical degradation, the loss of efficacy of the LLINs was more likely due to increased insecticide resistance in local vectors. None of the nets tested was effective against the wild An. gambiae (s.l.) strain, which exhibited a high level of resistance to the pesticides deltamethrin and permethrin used to impregnate the nets. The source of this high level of resistance may be the $k d r$ mechanism as the $\mathrm{L} 1014 \mathrm{~F}$ mutation was observed in high frequency in An. gambiae (s.l.). These findings are consistent with those reported in studies that have been conducted across the country and which indicate a rapid evolution of insecticide resistance in malaria vector populations $[49,50]$. However, other mechanisms, such as metabolic resistance, could also be involved $[49,51,52]$. It is worth mentioning that Mvoua is a village mainly inhabited by farmers. The locality is characterized by the presence of many banana plantations and cocoa trees, with a consistently high use of pesticides. As reported by KerahHinzoumbé et al. [53], a mosquito population could generate resistance to pyrethroids through exposure in areas where there is an extensive use of pesticides in agriculture.

\section{Conclusion}

The findings of this study highlight high and perennial malaria transmission in Mvoua, with the highest infection rate in Anopheles vectors observed in the short dry season. Three major vectors, namely An. funestus, An. coluzzii and An. gambiae, were responsible for the transmission of the disease. This vector displayed a high level of resistance to pyrethroid insecticides due to the $k d r$ mutation, but also probably due to metabolic mechanisms. Although there was a high level of LLIN possession among the households, universal coverage was not reached and LLINs found in the locality were no longer effective against the local An. gambiae (s.l.) strain. The National Malaria Control Program should provide the locality with new LLLNs every 3 years, as recommended by WHO. Preferably, to manage the high pyrethroid resistance observed, these LLNs should incorporate a synergist to block the action of detoxification enzymes. People should be educated on the use and maintenance of LLINs, with an emphasis on the importance of sleeping under LLINs irrespective of season, as well as on the damaging impact of detergents used for their washing.

\section{Abbreviations}

DDT: Dichlorodiphenyltrichloroethane; EIR: Entomological inoculation rate; ELISA CSP: Enzyme-linked immunosorbent assay to detect the circumsporozoite protein; HLC: Human landing catch method; kdr: Knockdown resistance; LLIN: Long-lasting insecticidal net; pHI: Proportionate hole index; WHOPES: World Health Organization Pesticides Evaluation Scheme. 


\section{Acknowledgements}

The authors express their sincere gratitude to all of the local population of Mvoua village and to the administrative and traditional authorities for their support.

\section{Authors' contributions}

$\mathrm{DMN}$ and $\mathrm{CN}$ designed the study and acquired the funding for the study. $\mathrm{CN}, \mathrm{AN}, \mathrm{AN}, \mathrm{DMN}$ and DRM carried out the field work. AN, CN, AN and DMN performed the laboratory analyses. DMN, AN and CN performed the data analysis. CN, PNA, PAA, JT and CFBB supervised the study. DMN and AN wrote the original draft. PNA, CN, JT, PAA and CFBB reviewed and edited the final draft. All authors read and approved the final manuscript.

\section{Funding}

This research was funded by the Royal Society of Tropical Medicine and Hygiene (RSTMH) through a small grant awarded to DM and the Wellcome Trust through a Wellcome Trust Training fellowship in public health and tropical medicine to CN (102543/Z/13/Z). The RSTMH and the Wellcome Trust have no role in the design of the study and collection, analysis, and interpretation of data and in writing the manuscript.

\section{Availability of data and materials}

The datasets generated and/or analysed during the current study are available from the corresponding author on reasonable request.

\section{Ethics approval and consent to participate}

The study was approved by the Cameroonian National Ethical Committee for Research on Human Health (Statement No 2018/07/20/CE/NRERSH/SP). One week before the beginning of field activities, the population received a notice of information explaining the objectives, methodology, expected benefits and possible risks of the study. A consent form was sought from the head of households and for participants aged $>18$ years for mosquito collection. They were given the opportunity to ask questions and they were informed that they are free to withdraw from the study at any time, without penalty or loss of benefits. At the end of each sampling period, all mosquito collectors were given anti-malaria prophylaxis based on artesunate/amodiaquine according to the national guide for malaria treatment.

\section{Consent for publication}

Not applicable.

\section{Competing interests}

The authors declare they have no competing interests.

\begin{abstract}
Author details
${ }^{1}$ Laboratory of Parasitology and Ecology, Faculty of Sciences, University of Yaoundé I, P.O. Box 812, Yaoundé, Cameroon. ${ }^{2}$ Institut de Recherche de Yaoundé (IRY), Organisation de Coordination pour la lutte Contre les Endémies en Afrique Centrale (OCEAC), P.O. Box 288, Yaoundé, Cameroon. ${ }^{3}$ Department of Biological Sciences, Faculty of Medicine and Pharmaceutical Sciences, University of Douala, P.O. Box 24157, Douala, Cameroon. ${ }^{4}$ Department of Parasitology and Microbiology, Centre for Research in Infectious Diseases (CRID), P.O. Box 13591, Yaoundé, Cameroon. ${ }^{5}$ Animal Organisms Laboratory, Faculty of Sciences, University of Douala, P.O. Box 24157, Douala, Cameroon.
\end{abstract}

Received: 17 August 2020 Accepted: 7 December 2020

Published online: 02 January 2021

\section{References}

1. World Health Organization. World malaria report. Geneva: World Health Organization; 2018.

2. Ntonifor $\mathrm{NH}$, Veyufambom S. Assessing the effective use of mosquito nets in the prevention of malaria in some parts of Mezam division, Northwest Region Cameroon. Malaria J. 2016;15(1):390.

3. National Malaria Control Programme (NMCP). NMCP annual report. Ministry of Public Health Cameroon; 2018.

4. Collins FH, Besansky NJ. Vector biology and the control of malaria in Africa. Science. 1994;264(5167):1874-5.
5. Antonio-Nkonjio C, Ndo C, Njiokou F, Bigoga J, Awono-Ambene P, Etang $J$, et al. Review of malaria situation in Cameroon: technical viewpoint on challenges and prospects for disease elimination. Parasites Vectors. 2019;12:501. https://doi.org/10.1186/s13071-019-3753-8.

6. Bigoga JD, Manga L, Titanji VPK, Coetzee M, Leke RGF. Malaria vectors and transmission dynamics in coastal south-western Cameroon. Malar J. 2007;6(1):5.

7. Ndo C, Kopya E, Donbou MA, Njiokou F, Awono-Ambene P, Wondji C. Elevated Plasmodium infection rates and high pyrethroid resistance in major malaria vectors in a forested area of Cameroon highlight challenges of malaria control. Parasites Vectors. 2018;11:157. https://doi.org/10.1186/ s13071-018-2759-y.

8. Institute of Medicine, Committee for the Study on Malaria Prevention and Control. Vector biology, ecology, and control. In: Oaks SC Jr, Mitchell VS, Pearson GW, Carpenter CCJ, editors. Malaria: obstacles and opportunities, vol. 7. Washington DC: The National Academy Press; 1991.

9. Ferguson HM, Dornhaus A, Beeche A, Borgemeister C, Gottlieb M, Mulla MS, et al.. Ecology: a prerequisite for malaria elimination and eradication. PLoS Med. 2010;7(8):e1000303.

10. Subbarao SK, Nanda N, Rahi M, Raghavendra K. Biology and bionomics of malaria vectors in India: existing information and what more needs to be known for strategizing elimination of malaria. Malar J. 2019;18(1):396.

11. World Health Organization. Guidelines for monitoring the durability of long-lasting insecticidal mosquito nets under operational conditions. Geneva:WHO/HTM/NTD/WHOPES; 2011.

12. World Health Organization. Recommendations for achieving universal coverage with long-lasting insecticidal nets in malaria control. Geneva: World Health Organization; 2013.

13. Suchel J-B. Les climats du Cameroun. PhD thesis. Bordeaux: Université de Bordeaux III; 1988.

14. Service M. Mosquito ecology. Field sampling methods. Essex: Elsevier Science Publishers; 1993.

15. Gillies MT, De Meillon B: The Anophelinae of Africa south of the Sahara (Ethiopian zoogeographical region), 2nd edn. Johannesburg: South African Institute of Medical Research; 1968.

16. Gillies MT, Coetzee M. A supplement to the Anophelinae of Africa South of the Sahara. Publ S Afr Inst Med Res. 1987;55:1-143.

17. Bukot TR, Williams JL, Schneider I. Identification of Plasmodium falciparum-infected mosquitoes by a double antibody enzyme-linked immunosorbent assay. Am J Trop Med Hyg. 1984;33(5):783-8.

18. Wirtz RA, Burkot TR, Graves PM, Andre RG. Field evaluation of enzymelinked immunosorbent assays for Plasmodium falciparum and Plasmodium vivax sporozoites in mosquitoes (Diptera: Culicidae) from Papua New Guinea. J Med Entomol. 1987;24(4):433-7.

19. Livak KJ. Organization and mapping of a sequence on the Drosophila melanogaster $X$ and $Y$ chromosomes that is transcribed during spermatogenesis. Genetics. 1984;107:611-34.

20. Fanello C, Santolamazza F, Torre AD. Simultaneous identification of species and molecular forms of the Anopheles gambiae complex by PCRRFLP. Med Vet Entomol. 2002;16(4):461-4.

21. Koekemoer LL, Kamau L, Hunt RH, Coetzee M. A cocktail polymerase chain reaction assay to identify members of the Anopheles funestus (Diptera: Culicidae) group. Am J Trop Med Hyg. 2002;66(804):811.

22. Hashmat I, Zarnigar Ghulamuddin S, Seikh A. The basic rules and methods of mosquito rearing (Aedes aegypti). Trop Parasitol. 2014;4(1):53-5.

23. World Health Organization. Test procedures for insecticide resistance monitoring in malaria vector mosquitoes. Geneva: World Health Organization; 2013

24. Abbott W. A method of computing the effectiveness of an insecticide. 1925. Am Mosq Control Assoc. 1987;3:302-3.

25. Martinez-Torres D, Chandre F, Williamson MS, Darriet F, Bergé JB, Devonshire AL, et al. Molecular characterization of pyrethroid knockdown resistance $(k d r)$ in the major malaria vector Anopheles gambiae s.s. Insect Mol Biol. 1988;7(2):179-84.

26. Eng JL, Chan A, Abílio AP, Wolkon A, de Leon GP, Gimnig J, et al. Bed net durability assessments: exploring a composite measure of net damage. PLoS One. 2015;10(6):e0128499.

27. Eng JL, Mathanga DP, Landman K, Mwandama D, Minta A, Shah M, et al. Assessing bed net damage: comparisons of three measurement methods for estimating the size, shape, and distribution of holes on bed nets. Malar J. 2017;16:405. 
28. Batisso E, Habate T, Tesfaye G, Getachew D, Tekalegne A, Kilian A, Mpeka B. A stitch in time: a cross-sectional survey looking at long lasting insecticide - treated bed net ownership, utilization and attrition in SNNPR, Ethiopia. Malar J. 2012;11:18.

29. Kilian A, Byamukama W, Pigeon O, Gimnig J, Atieli F, Koekemoer L, et al. Evidence for a useful life of more than 3 years for a polyester based long lasting insecticidal net in Western Uganda. Malar J. 2011;10:299.

30. World Health Organization. Guidelines for laboratory and field testing of long-lasting insecticidal mosquito nets. Geneva: World Health Organization; 2005.

31. Ntonga AP, Mbida JA, Tonga C, Belong P, Ngo-Hindt OE, Tamdem G, et al. Impact of vegetable crop agriculture on anopheline agressivity and malaria transmission in urban and less urbanized settings of the South region of Cameroon. Parasites Vectors. 2015;8(1):1-11. https://doi. org/10.1186/s13071-015-0906-2.

32. Overgaard HJ, Olano VA, Jaramillo JP, Matiz MI, Sarmiento D, Stenstrom TA, et al. A cross-sectional survey of Aedes aegypti immature abundance in urban and rural household containers in central Colombia. Parasites Vectors. 2017;10:356. https://doi.org/10.1186/s13071-017-2295-1.

33. Govella NJ, Chaki PP, Mpangile JM, Killeen GF. Monitoring mosquitoes in urban Dar es Salaam: evaluation of resting boxes, window exit traps, CDC light traps, Ifakara tent traps and human landing catches. Parasites Vectors. 2011;4:40. https://doi.org/10.1186/1756-3305-4-40

34. Kilama M, Smith DL, Hutchinson R, Kigozi R, Yeka A, Lavoy G, et al. Estimating the annual entomological inoculation rate for Plasmodium falciparum transmitted by Anopheles gambiae s.l. using three sampling methods in three sites in Uganda. Malar J. 2014;13:111.

35. Lima JB, Rosa-Freitas MG, Rodovalho CM, Santos F, Lourenço-de-Oliveira R. Is there an efficient trap or collection method for sampling Anopheles darlingi and other malaria vectors that can describe the essential parameters affecting transmission dynamics as effectively as human landing catches? A review. Mem Inst Oswaldo Cruz. 2014;109:685-705.

36. Briët OJT, Huho BJ, Gimnig JE, Bayoh N, Seyoum A, Sikaala CH, et al. Applications and limitations of centers for disease control and prevention miniature light traps for measuring biting densities of African malaria vector populations: a pooled-analysis of 13 comparisons with human landing catches. Malar J. 2015;14:247.

37. Lima J, Rosa-Freitas MG, Rodovalho C, Santos F, Oliveira R. Is there an efficient trap or collection method for sampling Anopheles darlingi and other malaria vectors that can describe the essential parameters affecting transmission dynamics as effectively as human landing catches? Mem Inst Oswaldo Cruz. 2014;109:685-705.

38. Cohuet A, Simard F, Wondji CS, Antonio-Nkondjio C, Awono-Ambene H, Fontenille D. High malaria transmission intensity due to Anopheles funestus (Diptera: Culicidae) in a village of savannah-rorest transmission area in Cameroon. J Med Ent. 2004;41:901-5.

39. Djamouko-Djonkam L, Nkahe DL, Kopya E, Talipouo A, Ngadjeu C, Doumbe B, et al.. Implication of Anopheles funestus in malaria transmission in the city of Yaoundé, Cameroon. Parasites. 2020;27:10.

40. Antonio-Nkondjio C, Awono-Ambene P, Toto JC, Meunier J-Y, ZebazeKemleu S, Nyambamet R, et al. High malaria transmission intensity in a village close to Yaounde, the Capital City of Cameroon. J Med Entomol. 2002:39(2):350-5.
41. Cavalie Ph, Mouchet J. La campagne d'éradication du paludisme dans le Nord de la République du Cameroun II Les opérations de lutte antipaludisque et leur résultats. Méd Trop. 1961;21:847-870.

42. Awono-Ambene P, Antonio-Nkondjio C, Toto J, Ndo C, Etang J, Fontenille $\mathrm{D}$, et al. Epidemological importance of the Anopheles nili group of malaria vectors in equatorial villages of Cameroon, Central Africa. Sci Med Afr. 2009;1:13-20.

43. Antonio-Nkondjio C, Demanou M, Etang J, Bouchite B. Impact of cyfluthrin (Solfac EW050) impregnated bed nets on malaria transmission in the city of Mbandjock: lessons for the nationwide distribution of long-lasting insecticidal nets (LLINs) in Cameroon. Parasites Vectors. 2013;6(1):10. https://doi.org/10.1186/1756-3305-6-10.

44. Kar NP, Ashwani K, Singh OM, Carlton JM, Nanda N. A review of malaria transmission dynamics in forest ecosystems. Parasites Vectors. 2014;7:265. https://doi.org/10.1186/1756-3305-7-265.

45. World Health Organization. Global malaria programme, Achieving universal coverage with long-lasting insecticidal nets in malaria control. Geneva: World Health Organization; 2014.

46. Ossè RA, Aikpon R, Sovi A, Padonou GG, Oké-Agbo F, Gnanguenon V, et al. Long lasting insecticidal nets use, efficacy and physical integrity in a vector resistance area after a nationwide campaign in southern Benin. West Africa. J Public Health Epidemiol. 2013;5:325-35.

47. Hill J, Lines J, Rowland M. Insecticide-treated nets. Adv Parasitol. 2006;61:77-128.

48. Morris S, Davies NW, Brown H, Groom T. Effect of drying conditions on pyrethrins content. Ind Crops Prod. 2006;23(1):9.

49. Menze B, Riveron JM, Ibrahim SS, Irving H, Antonio-Nkondjio C, AwonoAmbene $\mathrm{PH}$. Multiple insecticide resistance in the malaria vector Anopheles funestus from northern Cameroon is mediated by metabolic resistance alongside potential target site insensitivity mutations. PLoS One. 2016;11(10):e0163261.

50. Antonio-Nkondjio C, Sonhafouo-Chiana N, Ngadjeu CS, Doumbe-Belisse P, Talipouo A, Djamouko-Djonkam L, et al. Review of the evolution of insecticide resistance in main malaria vectors in Cameroon from 1990 to 2017. Parasites Vectors. 2017;10(1):472. https://doi.org/10.1186/s1307 1-017-2417-9.

51. Wondji CS, Irving H, Morgan J, Lobo NF, Collins FH, Hunt RH, et al. Two duplicated P450 genes are associated with pyrethroid resistance in Anopheles funestus, a major malaria vector. Genome Res. 2009;19(3):452-9.

52. Wondji CS, Dabire RK, Tukur Z, Irving H, Djouaka R, Morgan JC. Identification and distribution of a GABA receptor mutation conferring dieldrin resistance in the malaria vector Anopheles funestus in Africa. Insect Biochem Mol Biol. 2011;41(7):484-91.

53. Kerah-Hinzoumbé $C$, Péka $M$, Nwane $P$, Donan-Gouni I, Etang J, SamèEkobo A, et al. Insecticide resistance in Anopheles gambiae from southwestern Chad, Central Africa. Malar J. 2008;7:192.

\section{Publisher's Note}

Springer Nature remains neutral with regard to jurisdictional claims in published maps and institutional affiliations.
Ready to submit your research? Choose BMC and benefit from:

- fast, convenient online submission

- thorough peer review by experienced researchers in your field

- rapid publication on acceptance

- support for research data, including large and complex data types

- gold Open Access which fosters wider collaboration and increased citations

- maximum visibility for your research: over $100 \mathrm{M}$ website views per year

At BMC, research is always in progress.

Learn more biomedcentral.com/submissions 